\title{
Physicochemical and Antimicrobial Properties of Whey Protein-Based Films Functionalized with Palestinian Satureja capitata Essential Oil
}

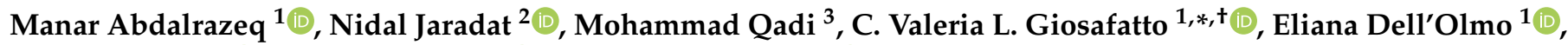 \\ Rosa Gaglione $^{1}{ }^{(D)}$, Angela Arciello ${ }^{1}$ and Raffaele Porta ${ }^{1,+}+\mathbb{D}$
}

1 Department of Chemical Sciences, University of Naples “Federico II", Via Cintia 4, I-80126 Naples, Italy; manar.abdalrazeq@unina.it (M.A.); eliana.dellolmo@unina.it (E.D.); rosa.gaglione@unina.it (R.G.); angela.arciello@unina.it (A.A.); raffaele.porta@unina.it (R.P.)

2 Department of Pharmacy, Faculty of Medicine and Health Sciences, An-Najah National University, Nablus 00970, Palestine; nidaljaradat@najah.edu

3 Department of Biomedical Sciences, Faculty of Medicine and Health Sciences, An-Najah National University, Nablus 00970, Palestine; m.qadi@najah.edu

* Correspondence: giosafat@unina.it

+ Center for Studies on Bioinspired Agro-Environmental Technology (BAT), University of Naples "Federico II", Naples, Italy.

Citation: Abdalrazeq, M.; Jaradat, N.; Qadi, M.; Giosafatto, C.V.L.; Dell'Olmo, E.; Gaglione, R.; Arciello, A.; Porta, R. Physicochemical and Antimicrobial Properties of Whey Protein-Based Films Functionalized with Palestinian Satureja capitata Essential Oil. Coatings 2021, 11, 1364. https://doi.org/10.3390/ coatings11111364

Academic Editor: Simona Liliana Iconaru

Received: 6 October 2021

Accepted: 3 November 2021

Published: 6 November 2021

Publisher's Note: MDPI stays neutral with regard to jurisdictional claims in published maps and institutional affiliations.

Copyright: (c) 2021 by the authors. Licensee MDPI, Basel, Switzerland. This article is an open access article distributed under the terms and conditions of the Creative Commons Attribution (CC BY) license (https:/ / creativecommons.org/licenses/by/ $4.0 /)$.
Abstract: The present study aimed to produce bio-active packaging materials made of whey proteins (WPs) and essential oil (EO) extracted from Thymbra (Satureja capitata, L.), one of the most popular Palestinian wild plants. In this study, two different Thymbra leaves from Nablus and Qabatiya in Palestine were collected and analyzed for EOs by gas chromatography and mass spectrometry. Based on the analysis, two EOs, namely, TEO1 and TEO2, were extracted, and it was found that both samples primarily contain $\gamma$-terpinene and carvacrol, whereas $p$-cymene was detected only in TEO1. The antimicrobial activity of TEO1 and TEO2 was evaluated by microbroth microdilution assays against pathogenic bacteria and yeast. Based on the results, TEO1 exhibited potent antimicrobial activity against the test strains. Besides, TEO1 was chosen to functionalize WP-based films at different concentrations $(0.1 \%, 0.4 \%$, and $0.8 \% v / v$ of Film Forming Solutions). Film mechanical property investigation showed a marked reduction in the tensile strength and Young's modulus at $0.8 \%$ TEO1. In contrast, its elongation at break value was significantly $(p<0.05)$ increased due to the plasticizing effect of the EO. Moreover, the film transparency was found to be significantly $(p<0.05)$ reduced by increasing TEO1 concentrations. Finally, microbiological investigations indicated that film antimicrobial activity against both gram-positive and gram-negative bacteria increased dose-dependently. The overall results open interesting perspectives for employing these films as preservative materials in food packaging.

Keywords: antimicrobial film; active packaging; food coating; whey proteins; essential oil

\section{Introduction}

Food packaging has a crucial role in protecting food products from the risk of pathogen growth, leading to an extension of food product shelf life [1,2]. So far, polyethylene terephthalate, polyethylene, and polyvinylchloride are the most common petrol-derived plastics, commonly used due to their availability at a relatively low cost [2], and because they possess excellent technical properties such as hardness, formability, rigidity, elasticity, heat, and chemical resistance [3]. Meanwhile, these conventional plastics are not biodegradable, and are thus considered today as being the most polluting materials on our planet [4]. Hence, scientists have started developing new strategies and production of alternative materials, such as bio-based polymers obtained from agricultural or food wastes. In this context, whey from the cheese industry is considered one of the most interesting and valuable food 
wastes to be recycled. Whey is the liquid that is formed following casein coagulation in the dairy industries, possessing a high organic content and a high percentage of proteins. As whey is rich in several nutrients important for the obtainment of further bioproducts, it would be advisable to recycle whey-containing liquid waste through an eco-friendly method. However, as a huge amount of whey goes unused, or is even disposed of illegally, researchers should develop innovative methods to get the maximum benefits from its use. In fact, whey proteins (WPs) derived from the cheese industry waste stream possess a high nutritional value and properties such as solubility in water and the ability to act as emulsifiers, which have been exploited for the manufacturing of transparent, flexible, colorless, and odorless bioplastics with poor moisture and $\mathrm{O}_{2}$ barrier properties. [5]. In the year 2017, the production of milk in the EU totaled 170 billion $\mathrm{kg}$, $93 \%$ of which resulted in dairy products, which includes cheese (37\%), butter (30\%), cream (13\%), fresh milk (11\%), acidified milk ( $4 \%)$, milk powder $(2 \%)$, and other minor products. Each liter of processed milk results, on an average, in $2.5 \mathrm{~L}$ of whey-containing wastewater, while about 9-10 L of whey is produced per $\mathrm{kg}$ of cheese [6]. Whey contains two main proteins, B-lactoglobulin, and $\alpha$-lactalbumin, endowed with important properties such as solubility, foaming, and gelling [7], making them of great interest for different biotechnological applications. In particular, WPs can give rise to edible bioplastic materials [8-12].

Aiming to improve food packaging features, many studies have exploited natural additives with antimicrobial and antioxidant activity to produce bio-active materials [13-15]. Interestingly, essential oils (EOs) extracted from different plants and edible herbs are considered potential additives for food packaging applications because of their biological features $[1,13,16,17]$.

Satureja capitata, an aromatic plant of the Lamiaceae family, commonly named "Thymbra" (Figure 1) and also known in Arabic as "za'atar rumi", "za'atar franji" and "za'atar farsi" [18] (meaning "Roman hyssop", "European hyssop", and "Persian hyssop", respectively), attracted our attention since it possesses some interesting features.

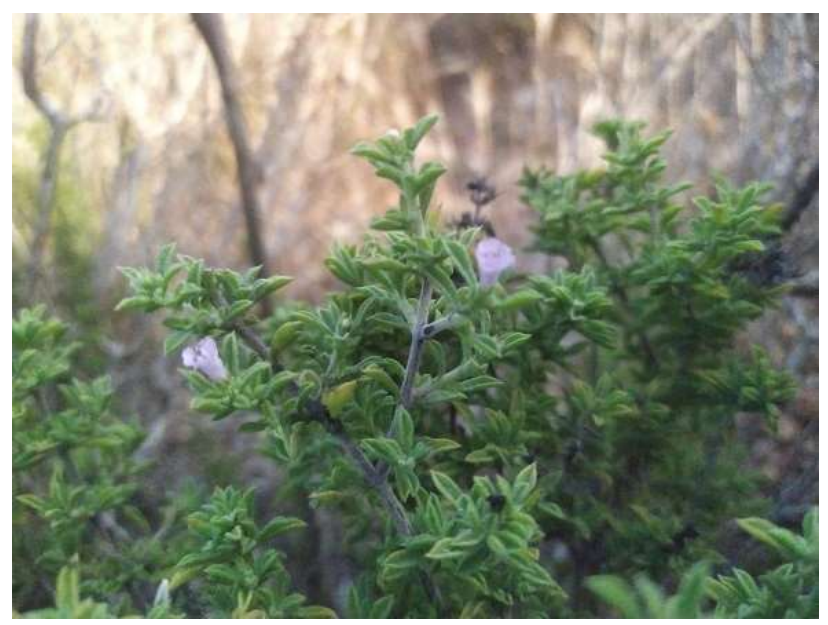

Figure 1. Palestinian Satureja capitata (Thymbra).

Thymbra has been used for more than 100 years by the Palestinians as a spice in some food, as well as an alternative medicine to treat tonsillitis. In fact, many scientific studies proved that this plant has powerful antibacterial, antifungal, and antiviral activities, while further investigations have shown that the extract from this plant can protect against coughing, respiratory infections, diarrhea, and digestive problems $[19,20]$. Therefore, this study has been addressed to extract Thymbra EOs (TEOs), to determine their composition, and to produce bioactive materials by incorporating the extracted TEOs into WP-based films. 


\section{Materials and Methods}

\subsection{Materials}

WP isolates ( $90 \%$ dry basis protein) were purchased from BioLine (London, UK). Clevenger apparatus (Esel International, Haryana, India) was used to extract EOs from Palestinian Thymbra; two different samples were used: one (TEO1) was obtained from a local shop in Nablus city, and the second sample (TEO2) was harvested from Qabatia mountain in the Jenin region, Palestine. Glycerol (GLY) and all other reagents were from Merck KGaA (Darmstadt, Germany). Different microorganisms were used to evaluate the antimicrobial activity of the different samples. In particular, the gram positive strains Staphylococcus aureus ATCC 25923, Enterococcus faecium ATCC 700221, Staphylococcus aureus ATCC 29213 and Enterococcus faecalis ATCC 29212 as well as the gram negative ones Klebsiella pneumoniae ATCC 13883, Escherichia coli ATCC 25922, Proteus vulgaris ATCC 8427, Pseudomonas aeruginosa ATCC 9027, Salmonella enterica subsp. enterica serovar Typhimurium (ATCC $^{\circledR}$ 14028) and the yeast Candida albicans ATCC 90028 were tested. In addition, the clinical pathogen methicillin-resistant Staphylococcus aureus (MRSA) and Salmonella enteriditis 706 RIVM were also used to evaluate TEO antimicrobial activity. FFSs and films were analyzed for their antimicrobial activity on the selected foodborne spoilage microorganisms (Salmonella enterica subsp. enterica serovar Typhimurium, Salmonella enteriditis 706 RIVM, Staphylococcus aureus and Enterococcus faecalis) by using Mueller Hinton Broth (Becton Dickinson Difco, Franklin Lakes, NJ, USA) or Tryptic Soy Agar (TSA) plates (Sigma Aldrich, Milan, Italy).

\subsection{Thymbra Essential Oil Extraction}

Thymbra leaves were obtained both from a local shop in Nablus and directly collected from Qabatiya mountains in Palestine. The first ones were already dry, whereas the second ones were previously dried in the oven (Huanghua Faithful Instrument Co., Ltd., Tianjin, China) at $30^{\circ} \mathrm{C}$ for $24 \mathrm{~h}$ before EO extraction. Then, TEOs were extracted from both dried leaf samples by steam-distillation for $3 \mathrm{~h}$ using a Clevenger type apparatus, according to a previously described method [21], and respectively named TEO1 and TEO2. $\mathrm{CaCl}_{2}$ was finally added to remove the remaining water, and both TEO samples were kept in a dark glass bottle at $4{ }^{\circ} \mathrm{C}$ before their characterization and use.

\subsection{Determination of Thymbra Essential Oil Composition}

Yields (\%) of extracted TEOs were calculated by dividing the TEO weight by the weight of Thymbra leaves. TEOs were then analyzed with a gas chromatography-mass spectrometry (Shimadzu QP-5000 GC-MS, Kyoto, Japan). The GC apparatus was equipped with a Rtx-5 MS column (30 m long, $0.25 \mu \mathrm{m}$ thickness, and $0.250 \mathrm{~mm}$ inner diameter), whereas helium was utilized as a carrier gas at a flow rate of $1 \mathrm{~mL} / \mathrm{min}$, and the injector temperature was $220^{\circ} \mathrm{C}$. The oven temperature started from $50{ }^{\circ} \mathrm{C}(1 \mathrm{~min}$ hold $)$ to $130^{\circ} \mathrm{C}$ $\left(5^{\circ} \mathrm{C} / \mathrm{min}\right)$, then to $250{ }^{\circ} \mathrm{C}\left(10^{\circ} \mathrm{C} / \mathrm{min}\right)$ and, finally, it was kept isothermally for $15 \mathrm{~min}$ (the transfer line temperature was $290^{\circ} \mathrm{C}$ ). For GC-MS detection, an electron ionization system, with detector volts of $1.7 \mathrm{KV}$, was used. A scan rate of $0.5 \mathrm{~s}$, and a scan speed of $1000 \mathrm{amu} / \mathrm{s}$ was applied, covering a mass range from 38 to $450 \mathrm{M} / \mathrm{Z}$. The chemical ingredients of the volatile oil were identified by correlating their mass spectra with the reference ones present of the mass spectrometry data center of the National Institute of Standards and Technology (NIST) [22].

\subsection{Antimicrobial Activity of Essential Oils Extracted from Thymbra Leaves}

Minimal inhibitory concentration (MIC) values of TEO were evaluated by using the method previously described [23] against different microorganisms such as S. aureus, E. coli, K. pneumoniae, P. vulgaris, E. faecium, P. aeruginosa, and C. albicans. In addition, the clinical pathogen MRSA was used to evaluate TEO antimicrobial activity. Briefly, TEOs were two-fold serially diluted in the freshly prepared sterile MHB medium and dispensed into a 96-well micro-titration plate. After that, each well was inoculated with bacterial 
inoculums, which were prepared from adjusted 0.5 McFarland microbial suspensions. Regarding the C. albicans, the same procedure was used by using RPMI media instead of Mueller-Hinton. After mixing, the 96 -well micro-titration plates were incubated at $37^{\circ} \mathrm{C}$ for $24 \mathrm{~h}$ for those plates inoculated with the test bacterial strains, and for about $48 \mathrm{~h}$ for those plates inoculated with C. albicans. MIC values were determined as the lowest antimicrobial agent concentration that prevents the visible microorganism growth. The experiment was carried out in triplicates and against each tested microbe, three controls were included. Two of them were negative controls, one consisting of the used MHB medium alone, and the other one consisting of MHB medium with the diluted TEOs to check the sterility of these materials. The third control used was a positive control consisting of antibiotics with known antimicrobial activity: ampicillin, ciprofloxacin, or fluconazole.

\subsection{Zeta Potential and Particle Size Measurements of Whey Protein Film-Forming Solutions (FFSs)}

To determine the FFS particle size and stability, $1.0 \mathrm{~mL}$ of each FFS was analyzed by a Zetasizer Nano-ZSP (Malvern ${ }^{\circledR}$, Worcestershire, UK) as reported in Abdalrazeq et al. [8]. Three measurements of each replicate were carried out.

\subsection{Antimicrobial Activity of Whey Protein Film-Forming Solutions}

S. enteriditis 706 RIVM, S. enterica ATCC ${ }^{\circledR}$ 14028, S. aureus ATCC 29213, and E. faecalis ATCC 29212 were grown in MHB or on TSA plates. All the strains were grown overnight at $37^{\circ} \mathrm{C}$. Afterward, the bacteria were diluted in fresh media as described below. To test the antimicrobial activity of the FFS, microbroth microdilution assay [24,25] followed by a colony count assay were carried out. Briefly, $50 \mu \mathrm{L}$ of bacterial cells at the final concentration of $2 \times 10^{6} \mathrm{CFU} / \mathrm{mL}$ were plated into 96-well plates. After that, $50 \mu \mathrm{L}$ of 2-fold serial dilution of the FFSs were added and, upon $24 \mathrm{~h}$ of incubation, $100 \mu \mathrm{L}$ of each sample were plated on TSA Petri dishes. The plates were incubated at $37^{\circ} \mathrm{C}$ for $24 \mathrm{~h}$ and, at the end of the incubation, colony counting was performed. FFSs in the absence of TEO, as well as the bacterial cells alone, were used as control samples. Experiments were carried out in triplicate.

\subsection{Whey Protein-Based Film Preparation}

For film preparation, FFSs were prepared as reported in Abdalrazeq et al. [8] by dissolving WP isolate $(5 \%, w / v)$ in distilled water and by adding 50\% GLY $(w / w$ of WPs) to the FFS. Hence, different concentrations of TEO1 $(0.1 \%, 0.4 \%$ or $0.8 \% v / v)$ were added or not to FFS aliquots. The films were prepared by casting the FFS samples $(25 \mathrm{~mL})$ onto $8 \mathrm{~cm}$ diameter polyethylene Petri dishes and by incubating the solutions in a climatic chamber set up at $25{ }^{\circ} \mathrm{C}$ and $45 \%$ relative humidity for $24 \mathrm{~h}$.

\subsection{Film Opacity Determination}

Film opacity was performed following the method of Shevkani et al. [26]. More in detail, $1 \mathrm{~cm} \times 4 \mathrm{~cm}$ film strips were let to adhere perfectly to a cuvette wall. Absorbance was detected at $600 \mathrm{~nm}$ and the opacity was obtained as,

$$
\text { Opacity }=\mathrm{A}_{600 \mathrm{~nm}} / \mathrm{X},
$$

where $A_{600 \mathrm{~nm}}$ and $X$ were the absorbance recorded at $600 \mathrm{~nm}$ and the film thickness $(\mathrm{mm})$, respectively.

\subsection{Film Thickness and Mechanical Properties}

WP-based film strips with a dimension of $1 \mathrm{~cm} \times 8 \mathrm{~cm}$ were obtained with a sharp scissor and then equilibrated for $48 \mathrm{~h}$ at $25^{\circ} \mathrm{C}$ and $50 \%$ relative humidity into a glass chamber containing a saturated solution of $\mathrm{Mg}\left(\mathrm{NO}_{3}\right)_{2}$ before the characterization. Film thickness was measured by means of a micrometer (Electronic digital micrometer, DC-516, sensitivity $0.001 \mathrm{~mm}$, Metrology Co., Pontoglio, Italy) at six different points of each film, whereas the determination of film tensile strength (TS), elongation at break (EB), and 
Young's modulus (YM) were performed on five specimens of each sample $(5 \mathrm{~cm}$ gage length, $1 \mathrm{kN}$ load and $5 \mathrm{~mm} / \mathrm{min}$ speed) with an Instron universal testing instrument model no. 5543A (Instron Engineering Corp., Norwood, MA, USA).

\subsection{Film Moisture Content and Uptake}

Samples of each film $(2 \mathrm{~cm} \times 2 \mathrm{~cm})$ were weighed and dried at $105^{\circ} \mathrm{C}$ in an oven for $24 \mathrm{~h}$. Analyses in triplicate were made and film moisture content was obtained as:

$$
\text { Film moisture content }(\%)=\left(\frac{\left(W_{1}-W_{2}\right)}{W_{1}}\right) \times 100
$$

where $W_{1}$ is the initial weight of the film and $W_{2}$ is the film weight after drying at $105^{\circ} \mathrm{C}$.

Moisture uptake was measured gravimetrically in triplicate following the methodology described by Sartori and Menegalli [27]. Briefly, $20 \mathrm{~mm}$-sided square film samples were dried at $105^{\circ} \mathrm{C}$ for $24 \mathrm{~h}$, conditioned at $23 \pm 2{ }^{\circ} \mathrm{C}$ into a desiccator containing a saturated $\mathrm{Mg}\left(\mathrm{NO}_{3}\right)_{2}$ solution, and weighed. The moisture uptake was obtained as:

$$
\text { Film moisture uptake }(\%)=\left(\frac{\left(W_{s}-W_{d}\right)}{W_{s}}\right) \times 100
$$

where $W s$ and $W d$ are the weight of swollen and dried films, respectively.

\subsection{Antimicrobial Properties of Whey Protein Films}

Bacterial cells were grown in Muller Hinton Broth (MHB, Becton Dickinson Difco, Franklin Lakes, NJ, USA)and on TSA. In all the experiments, bacteria were inoculated and grown overnight in $\mathrm{MHB}$ at $37^{\circ} \mathrm{C}$. The next day, bacteria were transferred to a fresh medium and grown to the mid-logarithmic phase. The antimicrobial activity of the WP-based films derived from FFSs, containing or not containing TEO1, was tested by the previously described method [25]. Briefly, bacterial cells were diluted into tryptic soy broth till $2 \times 10^{7} \mathrm{CFU} / \mathrm{mL}$ and spread onto TSA plates. A $1.5 \mathrm{~cm}^{2}$ square of the edible film was placed into an inoculated plate to allow full contact with the agar surface. Following incubation at $37^{\circ} \mathrm{C}$ for $24 \mathrm{~h}$, the microorganism growth underneath the film was investigated.

\subsection{Statistical Analysis}

Statistical analyses were carried out utilizing JMP software 5.0 (SAS Institute, Cary, NC, USA, version 10.0). The analysis of variance was performed, and the means were compared with the Tukey-Kramer HSD test. Differences were considered significant at $p<0.05$. Significant differences highlighted by Student's $t$-Test were indicated as ${ }^{*} p<0.05$ or ${ }^{* *} p<0.01$.

\section{Results and Discussion}

\subsection{Chemical Composition of Thymbra Essential Oils}

It is well known that several parameters affect the percentage yield of plant EO extraction, including soil, genetics, geographic origin, maturity degree, different organs, temperature, and relative humidity conditions, extract distillation time, and, finally, pressure and temperature of distillation $[21,23,28]$. In the present study, the TEO1 percentage yield was found to be $2.36 \%$, whereas the TEO2 yield was $3.07 \%$. In addition, notable quantitative and qualitative differences were observed in the components identified by analyzing with GC-MS the two different extracted TEOs. In fact, as shown in Table 1, the major identified volatile compounds detected in TEO1 were $\gamma$-terpinene, carvacrol, and p-cymene with the following percentages, $38.95 \%, 22.96 \%$, and $19.53 \%$, respectively, whereas in TEO2 samples the $\gamma$-terpinene content was higher, with a percentage of $57.81 \%$, and no p-cymene was detected. 
Table 1. Chemical composition of Thymbra essential oils.

\begin{tabular}{ccc}
\hline Component & TEO1 & TEO2 \\
\hline$\alpha$-Phellandrene & 1.65 & 3.16 \\
$\delta$-3-Carene & 1.48 & 1.44 \\
Camphene & 0.36 & 0.36 \\
$\beta$-Pinene & 0.41 & 0.36 \\
$\alpha$-Pinene & 1.10 & - \\
$\alpha$-Terpinolene & 7.19 & 0.26 \\
p-Cymene & 19.53 & - \\
Ortho-Cymene & - & 0.48 \\
$\gamma$-Terpinene & 38.95 & 57.81 \\
$\psi$-Limonene & 0.69 & - \\
$\alpha$-Terpinenol & 0.05 & 4.31 \\
Anisole & 0.67 & - \\
Thymol & 1.07 & 0.95 \\
Carvacrol & 22.96 & 23.2 \\
Caryophyllene & 2.63 & 4.40 \\
Linalool & - & 1.06 \\
Endo-Borneol & - & 0.20 \\
$\alpha$-Humulene & - & 0.14 \\
$\gamma$-Elemene & - & 0.10 \\
Total identified & 98.74 & 98.26 \\
Others & 1.26 & 1.74 \\
\hline
\end{tabular}

\subsection{Antimicrobial Activity of Thymbra Essential Oil Samples}

As reported in Table 2, TEO antimicrobial activity was investigated against gramnegative bacteria (E. coli ATCC 25922, K. pneumoniae ATCC 13883, P. vulgaris ATCC 8427, and P. aeruginosa ATCC 9027), and gram-positive bacteria (E. faecium ATCC 700221, S. aureus ATCC 25923, and the clinical pathogen S. aureus MRSA). Besides, TEO antimicrobial activity was also tested against $C$. albicans ATCC 90028 . MIC $_{100}$ values of both TEO samples revealed a powerful antimicrobial property towards both gram-positive and gram-negative bacteria, as well as against the fungal strain, even though TEO1 showed a stronger inhibitory effect than TEO2 against all the studied microorganisms. it is also possible to see that the investigated Palestinian TEOs exhibited stronger antimicrobial activity in comparison with that exerted by TEOs extracted from Turkish Thymbra previously analyzed by Baydar et al. [19]. In fact, the Turkish Thymbra EOs inhibited the microorganism growth at concentrations $<1 / 100(v / v)$, whereas the Palestinian TEOs showed antimicrobial effects at concentrations $<1 / 800$ (TEO1) or $<1 / 400$ (TEO2) $(v / v)$.

Table 2. MIC $\mathrm{M}_{100}$ values were determined for Thymbra essential oils against different microorganisms.

\begin{tabular}{|c|c|c|c|c|c|c|c|c|}
\hline ATCC \# & 25923 & 25922 & 13883 & 8427 & 700221 & 9027 & Clinical Strain & 90028 \\
\hline $\begin{array}{l}\text { Strains } \\
\text { name }\end{array}$ & $\begin{array}{l}\text { Staphylococcus } \\
\text { aureus }\end{array}$ & $\begin{array}{l}\text { Escherichia } \\
\text { coli }\end{array}$ & $\begin{array}{c}\text { Klebsiella } \\
\text { pneumoniae }\end{array}$ & $\begin{array}{l}\text { Proteus } \\
\text { vulgaris }\end{array}$ & $\begin{array}{l}\text { Enterococcus } \\
\text { faecium }\end{array}$ & $\begin{array}{c}\text { Pseudomonas } \\
\text { aeruginosa }\end{array}$ & $\begin{array}{c}\text { Methicillin- } \\
\text { Resistant } \\
\text { Staphylococcus } \\
\text { aureus (MRSA) }\end{array}$ & $\begin{array}{l}\text { Candida } \\
\text { albicans }\end{array}$ \\
\hline $\begin{array}{l}\mathrm{MIC}_{100} \\
\text { TEO1 }\end{array}$ & $1 / 1600$ & $1 / 800$ & $1 / 800$ & $1 / 1600$ & $1 / 800$ & $1 / 1600$ & $1 / 800$ & $1 / 800$ \\
\hline $\begin{array}{l}\mathrm{MIC}_{100} \\
\text { TEO2 }\end{array}$ & $1 / 800$ & $1 / 800$ & $1 / 400$ & $1 / 800$ & $1 / 400$ & $1 / 800$ & $1 / 400$ & $1 / 400$ \\
\hline
\end{tabular}




\subsection{Characterization of the Film-Forming Solution Containing Thymbra Essential Oil}

The particle size and zeta potential values of WP-based FFSs containing $0.8 \%$ TEO1 indicate a notable reduction in the particle size, most likely due to the formation of emulsions in the presence of EO, and that FFS stability slightly decreased by increasing TEO1 concentration (Figure 2).

A)

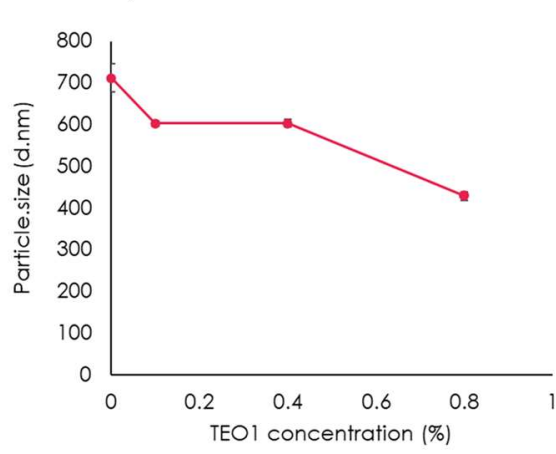

B)

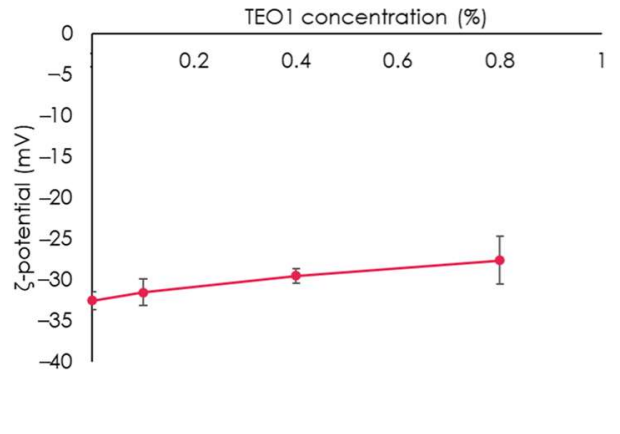

Figure 2. Particle size and zeta potential of WP-based FFSs prepared in the presence of different concentrations of TEO1 $(v / v)$. Values are the mean \pm SD. (A) particle size, (B) zeta potential.

To determine the ability of WP-containing FFSs to inhibit microbial growth, $\mathrm{MIC}_{100}$ values were calculated by carrying out dose-response experiments. WP FFSs prepared in the absence of TEO1 showed a slight antimicrobial activity towards all the strains tested. Conversely, the FFSs containing the lowest concentration tested $(0.1 \%)$ of TEO1 were able to totally suppress the bacterial growth in the case of the gram-negative bacteria S. enteriditis 706 RIVM, S. enterica subsp. enterica serovar Typhimurium (ATCC ${ }^{\circledR} 14028$ ) and the grampositive S. aureus ATCC 29213 (Figure 3A-C, respectively). Moreover, in the case of E. faecalis ATCC 29212, FFS containing 0.1\% TEO was found to inhibit the bacterial growth by about $50 \%$, whereas complete inhibition was observed in the presence of $0.4 \%$ TEO1 (Figure 3D).

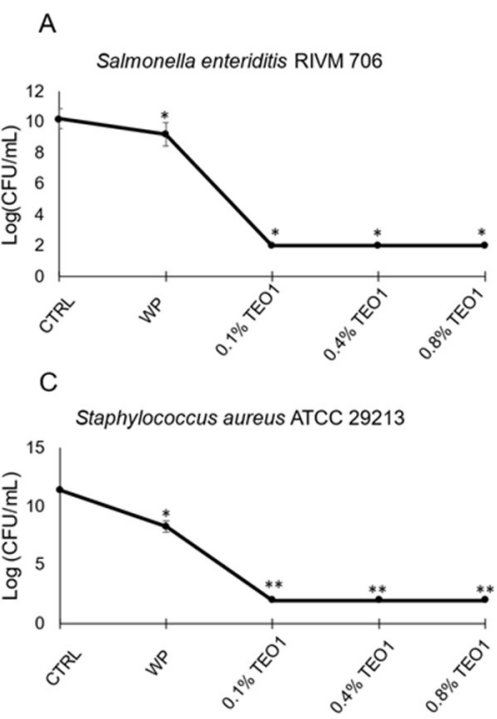

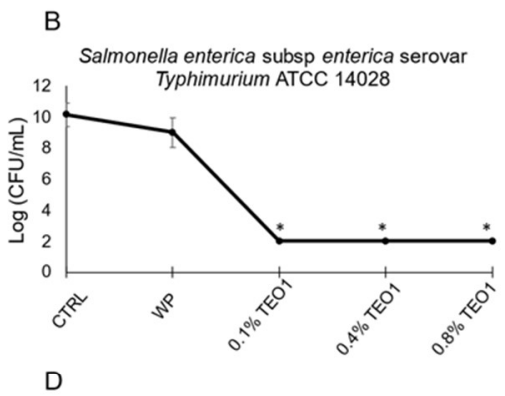

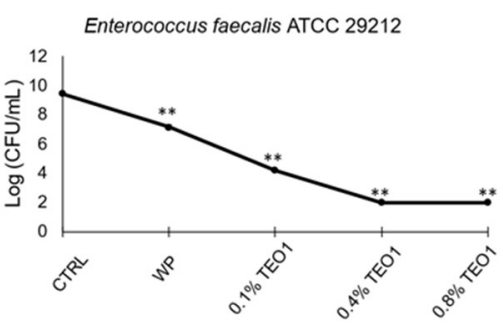

Figure 3. Effects of whey protein (WP) FFSs containing increasing concentrations of Thymbra essential oil 1 (TEO1) on the growth of different microorganisms. The effects on bacterial growth were evaluated upon incubation at $37^{\circ} \mathrm{C}$ overnight. Colony counting assays were carried out to determine $\mathrm{MIC}_{100}$ values. Data reported in the graphs represent the mean and the SD of the values collected in three independent experiments. (A) is S. enteriditis RIVM 706, (B) is S. enterica subsp. enterica serovar Typhimurium ATCC ${ }^{\circledR} 14028,(C)$ is S. aureus ATCC $^{\circledR} 29213$, (D) is E. faecalis ATCC $^{\circledR} 29212$. 


\subsection{Opacity, Thickness, and Mechanical Properties of Films Functionalized with Thymbra Essential Oil}

The transparency of EO-containing films is affected by the oil volume fraction and droplet size distribution in the FFS, as well as by the droplet rearrangement during FFS drying $[29,30]$. Moreover, the solvent evaporation of the solvent during the FFS drying may cause changes in the emulsion structure (i.e., creaming, aggregation, and/or coalescence), influencing the film optical properties [31]. The results illustrated in Figure 4 show a considerable decrease in the WP-based film transparency by increasing TEO1 concentration.

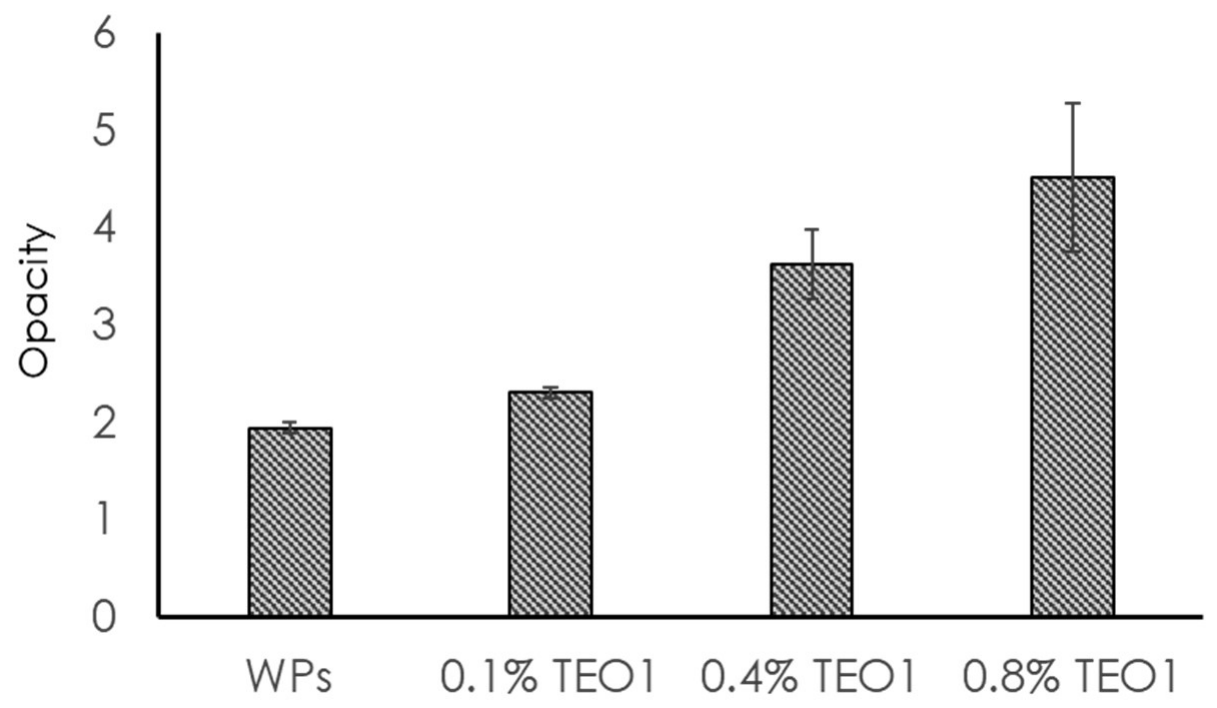

Figure 4. Opacity of WP (500 mg)-based films prepared either in the absence or presence of different concentrations of Thymbra essential oil (TEO1) $(\%, v / v)$. Values are mean \pm SD and the different letters indicate significant differences in the values (Tukey-Kramer test, $p<0.05$ ).

These findings are very similar with those previously reported by Galus et al. [30], who prepared and characterized WP-based films containing rapeseed oil. In addition, Figure 5 indicates that no differences were observed among the thickness of the WP-films prepared in the absence or presence of different TEO1 concentrations, whereas the mechanical feature investigation of TEO1-containing films demonstrated a progressive decrease in film TS by increasing TEO1 concentrations. Conversely, a marked decrease in the film YM value and an appreciable increase in the EB were observed only at the highest TEO1 concentration tested. All these data clearly demonstrate an increased plasticizing effect triggered by TEO1 addition to the WP-based FFSs. It is worthy to note that the results obtained in this study are close with those obtained on whey protein isolate-based films into which different concentrations of tarragon oil were added [32]. In fact, an improvement of the technological attitude of the films, e.g., enhanced mechanical properties and higher transparency were found following the tarragon oil incorporation [32]. 
A)

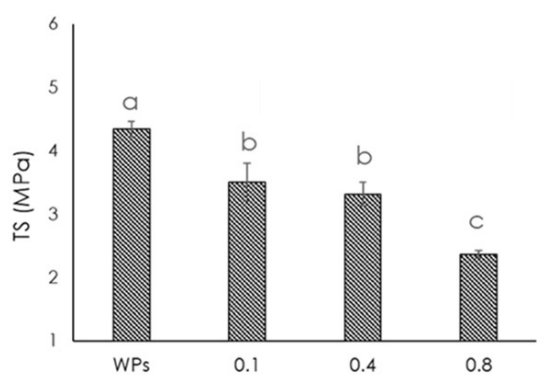

C) TEOI concentration (\%)

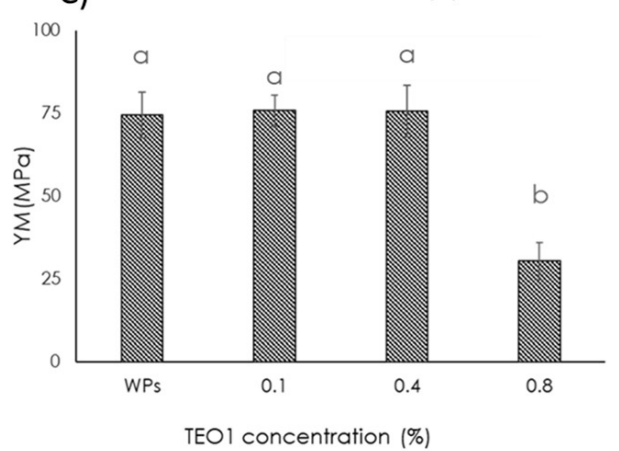

B)

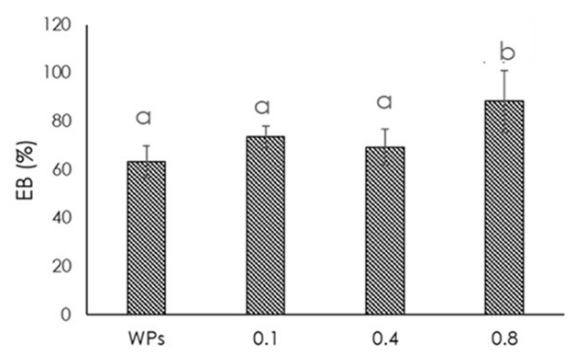

D)

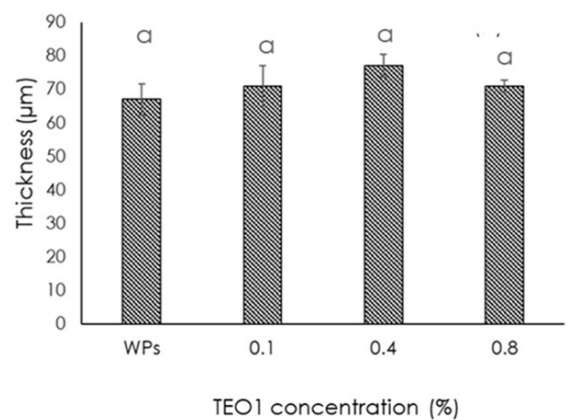

Figure 5. Thickness and mechanical properties of WP (500 mg)-based films prepared either in the absence or presence of different concentrations of Thymbra essential oil (TEO1) $(\%, v / v)$. Values are the mean $\pm \mathrm{SD}$ and the different letters indicate significant differences in the values (Tukey-Kramer test, $p<0.05)$. (A) tensile strength (TS), (B) elongation at break (EB), (C) Young's modulus (YM), (D) Thickness.

\subsection{Moisture Content and Uptake of Whey Protein Films Containing Thymbra Essential Oil}

Moisture content of WP-based films progressively decreased following the addition of increasing concentrations of TEO1 into the originating FFSs (Table 3). It is worthy to note that even at very low concentrations $(0.1 \%)$, TEO1 was effective to reduce the film moisture content. These results reflected those from Galus et al. [30], who investigated WP-based materials containing rapeseed oil. On the other hand, slight, even though not statistically significant, increases of moisture uptake were also observed. Similar data were obtained by Salarbashi et al. [33], who analyzed moisture uptake of soluble soybean/polysaccharide films incorporated with Zataria multiflora Boiss (Shirazi thyme).

Table 3. Moisture content and uptake of WP (500 mg)-based films prepared containing or not different concentrations of Thymbra essential oil (TEO1) *.

\begin{tabular}{ccc}
\hline Film & $\begin{array}{c}\text { Moisture Content } \\
(\mathbf{\%})\end{array}$ & $\begin{array}{c}\text { Moisture Uptake } \\
\mathbf{( \% )}\end{array}$ \\
\hline Control sample & $22.3 \pm 2.6^{\mathrm{a}}$ & $11.3 \pm 2.9^{\mathrm{a}}$ \\
$+0.1 \%(v / v)$ TEO1 & $20.3 \pm 1.8^{\mathrm{a}, \mathrm{b}}$ & $11.7 \pm 2.5^{\mathrm{a}}$ \\
$+0.4 \%(v / v)$ TEO1 & $18.5 \pm 1.4^{\mathrm{a}, \mathrm{b}}$ & $12.1 \pm 1.1^{\mathrm{a}}$ \\
$+0.8 \%(v / v)$ TEO1 & $17.5 \pm 0.7^{\mathrm{b}}$ & $13.3 \pm 0.8^{\mathrm{a}}$ \\
\hline
\end{tabular}

*Values are the mean \pm SD and the different letters indicate significant differences of the values reported in the same column (Tukey-Kramer test, $p<0.05$ ).

\subsection{Determination of the Antimicrobial Activity of Whey Protein Films Containing Thymbra Essential Oil}

Figure 6 shows the antimicrobial activity of the WP-based films, prepared in the absence or presence of TEO1, towards S. enteriditis 706 RIVM, S. enterica ATCC ${ }^{\circledR} 14028$, 
S. aureus ATCC 29213, and E. faecalis ATCC 29212 strains, observed by placing small squares $(1.5 \mathrm{~cm} \times 1.5 \mathrm{~cm})$ of each film on a confluent bacterial plate in full contact with the agar surface $[34,35]$.

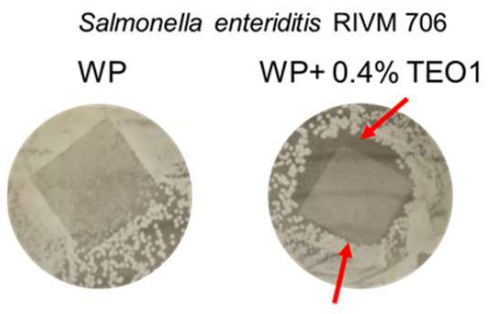

Salmonella typhimurium ATCC 14028

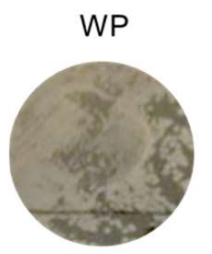

WP+ $0.4 \%$ TEO1

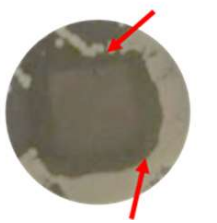

Staphylococcus aureus ATCC 29213

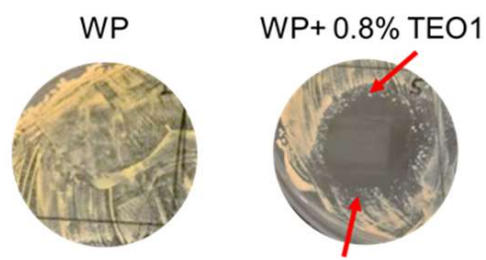

Enterococcus faecalis ATCC 29212

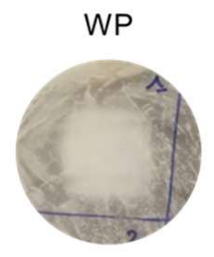

Figure 6. Antimicrobial effects of whey protein (WP)-based films, prepared either without or with Thymbra essential oil (TEO1). Antimicrobial effects were evaluated by analyzing the growth of the different bacterial cells held in direct contact with the films. The experiments were carried out in triplicate.

After $24 \mathrm{~h}$ at $37^{\circ} \mathrm{C}$, it was observed that the WP-based film itself was unable to inhibit bacterial growth (Figure 6). On the contrary, the films containing TEO1 at the highest concentration tested $(0.8 \%)$ showed a strong antimicrobial activity towards S. enteriditis 706 RIVM, S. enterica ATCC ${ }^{\circledR} 14028$ as well as against S. aureus ATCC 29213. Interestingly, it was also possible to observe a zone of inhibition surrounding the films activated with TEO1, thus, suggesting the ability of TEO1 to diffuse from the film into the agar matrix. Furthermore, no antimicrobial activity of the films was observed against E. faecalis ATCC 29212 even at the highest TEO1 concentration tested. The data presented in this paper are comparable to those obtained by Bleoancă et al. [36] who produced films from high pressure thermally treated whey protein concentrate into which the extracts were added. The authors have demonstrated the ability of the film matrix to vehicular the bioactive molecules, as they were endowed with good antimicrobial properties as demonstrated by the inhibition zones towards three fresh food spoilage microorganisms such Torulopsis stellata, Geotrichum candidum, and Bacillus subtilis [36].

\section{Conclusions}

EOs extracted from two different samples of Palestinian Thymbra (Satureja capitata, L.) leaves were analyzed for their composition and antimicrobial activity. Among these, the most promising antimicrobial agent was incorporated into WP-based edible films and evaluated for its ability to control the microbial growth. TEO1, showing higher antimicrobial properties most likely due to the presence of p-cymene, was included in the FFSs and the derived films were shown to possess improved mechanical properties, decreased moisture content, and exhibited a marked antimicrobial activity towards $S$. enteriditis, S. enterica and S. aureus. Regarding the E. faecalis bacterial strain, while FFSs were found to exert pronounced antimicrobial properties, no noteworthy effects of the films were detected. Furthermore, the observed zone of inhibition surrounding the films activated with TEO1 suggested the ability of TEO1 to diffuse into the agar matrix. Therefore, TEO1 may represent an effective bioactive additive of protein-based materials to be used in food packaging against specific spoilage bacterial strains. To this purpose, more investigations 
are still required to effectively examine the ability of WP-based bio-active packaging material functionalized with TEO1 in extending the shelf-life of some food.

Author Contributions: Conceptualization, C.V.L.G., R.P., A.A., M.A., N.J. and M.Q.; methodology, N.J., M.A., M.Q. and E.D.; software, R.G.; formal analysis, A.A., R.G., E.D., M.A. and N.J.; investigation, R.P., C.V.L.G., N.J. and M.A.; data curation, E.D., M.A. and R.G.; writing-original draft preparation, M.A., N.J. and M.Q.; writing-review and editing, R.P. and C.V.L.G.; supervision, R.P., C.V.L.G. and N.J. All authors have read and agreed to the published version of the manuscript.

Funding: This research was funded by the grant PRIN: Progetti di Ricerca di Interesse NazionaleBando 2017- “CARDoon valorisation by InteGrAted biorefiNery (CARDIGAN)” of Italian Ministero dell'Università e della Ricerca (COD. 2017KBTK93).

Institutional Review Board Statement: Not applicable.

Informed Consent Statement: Not applicable.

Data Availability Statement: All data generated or analysed during this study are included in this published article.

Acknowledgments: We would like to knowledge An-Najah National University for hosting Manar Abdalrazeq (MA). We also thank Maria Fenderico for her helpful technical assistance.

Conflicts of Interest: The authors declare no conflict of interest.

\section{References}

1. Çakmak, H.; Özselek, Y.; Turan, O.Y.; Firatlıgil, E.; Güler, F.K. Whey protein isolate edible films incorporated with essential oils: Antimicrobial activity and barrier properties. Polym. Degrad. Stab. 2020, 179, 109285. [CrossRef]

2. Galus, S.; Kadzińska, J. Gas barrier and wetting properties of whey protein isolate-based emulsion films. Polym. Eng. Sci. 2019, 59, E375-E383. [CrossRef]

3. Thielen, M. 'Bioplastics', Fachagentur Nachwachsende Rohstoffe e. V. (FNR) Agency for Renewable Resources. 2014. Available online: https://mediathek.fnr.de/media/downloadable/files/samples/b/r/brosch.biokunststoffe-web-v01_1.pdf (accessed on 1 August 2020).

4. Rajendran, N.; Puppala, S.; Sneha Raj, M.; Ruth Angeeleena, B.; Rajam, C. Seaweeds can be a new source for bioplastics. J. Pharm. Res. 2012, 5, 1476-1479.

5. Schmid, M.; Müller, K. Whey protein-based packaging films and coatings. In Whey Proteins; Elsevier: London, UK, 2019; pp. 407-437.

6. Milk and Milk Product Statistics—Statistics Explained. Available online: https://ec.europa.eu/eurostat/statistics-explained/ index.php?title=Milk_and_milk_product_statistics\&oldid=511480 (accessed on 7 April 2021).

7. Norwood, E.-A.; Croguennec, T.; Le Floch-Fouéré, C.; Schuck, P.; Jeantet, R. Chapter 4: Changes in whey protein powders during storage. In Whey Proteins; Deeth, H.C., Bansal, N., Eds.; Academic Press: New York, NY, USA, 2019; pp. 123-154. [CrossRef]

8. Abdalrazeq, M.; Giosafatto, C.V.L.; Esposito, M.; Fenderico, M.; Di Pierro, P.; Porta, R. Glycerol-plasticized films obtained from whey proteins denatured at alkaline $\mathrm{pH}$. Coatings 2019, 9, 322. [CrossRef]

9. Mahmoud, R.; Savello, P.A. Mechanical properties of and water vapor transferability through whey protein films. J. Dairy Sci. 1992, 75, 942-946. [CrossRef]

10. Maté, J.I.; Krochta, J.M. Whey protein coating effect on the oxygen uptake of dry roasted peanuts. J. Food Sci. 1996, 61, 1202-1207. [CrossRef]

11. Schmid, M.; Krimmel, B.; Grupa, U.; Noller, K. Effects of thermally induced denaturation on technological-functional properties of whey protein isolate-based films. J. Dairy Sci. 2014, 97, 5315-5327. [CrossRef] [PubMed]

12. Di Pierro, P.; Mariniello, L.; Giosafatto, V.L.; Esposito, M.; Sabbah, M.; Porta, R. Dairy whey protein-based edible films and coatings for food preservation. In Food Packaging and Preservation; Elsevier: Cambridge, MA, USA, 2018; pp. 439-456.

13. Zinoviadou, K.G.; Koutsoumanis, K.P.; Biliaderis, C.G. Physico-chemical properties of whey protein isolate films containing oregano oil and their antimicrobial action against spoilage flora of fresh beef. Meat Sci. 2009, 82, 338-345. [CrossRef]

14. Shojaee-Aliabadi, S.; Hosseini, H.; Mohammadifar, M.A.; Mohammadi, A.; Ghasemlou, M.; Ojagh, S.M.; Hosseini, S.M.; Khaksar, R. Characterization of antioxidant-antimicrobial k-carrageenan films containing Satureja hortensis essential oil. Int. J. Biol. Macromol. 2013, 52, 116-124. [CrossRef] [PubMed]

15. Pranoto, Y.; Salokhe, V.M.; Rakshit, S.K. Physical and antibacte rial properties of alginate-based edible film incorporated with garlic oil. Food Res. Int. 2005, 38, 267-272. [CrossRef]

16. Jaradat, N.; Al-Masri, M.; Zaid, A.N.; Hussein, F.; Al-Rimawi, F.; Abu Mokh, A.; Mokh, J.A.; Ghonaim, S. Phytochemical, antimicrobial and antioxidant preliminary screening of a traditional Palestinian medicinal plant, Ononis pubescens L. Eur. J. Integr. Med. 2017, 14, 46-51. [CrossRef] 
17. Jaradat, N.; Adwan, L.; K'Aibni, S.; Zaid, A.N.; Shtaya, M.; Shraim, N.; Assali, M. Variability of chemical compositions and antimicrobial and antioxidant activities of Ruta chalepensis leaf essential oils from three Palestinian regions. BioMed Res. Int. 2017, 2017, 2672689. [CrossRef] [PubMed]

18. Satureja thymbra. Wikipedia. 21 July 2020. Available online: https://en.wikipedia.org/w/index.php?title=Satureja_thymbra\& oldid=1013634228 (accessed on 11 April 2021).

19. Baydar, H.; Sagdic, O.; Ozkan, G.; Karadoğan, T. Antibacterial activity and composition of essential oils from Origanum, Thymbra and Satureja species with commercial importance in Turkey. Food Control 2004, 15, 169-172. [CrossRef]

20. Şahin, F.; Karaman, I.; Güllüce, M.; Öğütçü, H.; Şengül, M.; Adiguzel, A.; Öztürk, S.; Kotan, R. Evaluation of antimicrobial activities of Satureja hortensis L. J. Ethnopharmacol. 2003, 87, 61-65. [CrossRef]

21. Dadalioğlu, I.; Evrendilek, G.A. Chemical compositions and antibacterial effects of essential oils of turkish oregano (Origanum minutiflorum), bay laurel (Laurus nobilis), Spanish Lavender (Lavandula stoechas L.), and Fennel (Foeniculum vulgare) on Common Foodborne Pathogens. J. Agric. Food Chem. 2004, 52, 8255-8260. [CrossRef] [PubMed]

22. Sparkman, O.D. Identification of essential oil components by gas chromatography / mass spectroscopy Robert P. Adams. J. Am. Soc. Mass Spectrom. 1997, 8, 671-672. [CrossRef]

23. Dhifi, W.; Bellili, S.; Jazi, S.; Bahloul, N.; Mnif, W. Essential oils' chemical characterization and investigation of some biological activities: A critical review. Medicines 2016, 3, 25. [CrossRef] [PubMed]

24. Gaglione, S.; Innac, A.; Carbone, S.P.; Troisi, S.; Angrisano, A. Robust estimation methods applied to GPS in harsh environments. In Proceedings of the 2017 European Navigation Conference (ENC), Lausanne, Switzerland, 9-12 May 2017 ; pp. 14-25.

25. Dell'Olmo, E.; Gaglione, R.; Sabbah, M.; Schibeci, M.; Cesaro, A.; Di Girolamo, R.; Porta, R.; Arciello, A. Host defense peptides identified in human apolipoprotein B as novel food biopreservatives and active coating components. Food Microbiol. 2021, 99, 103804. [CrossRef]

26. Shevkani, K.; Singh, N. Relationship between protein characteristics and film-forming properties of kidney bean, field pea and amaranth protein isolates. Int. J. Food Sci. Technol. 2015, 50, 1033-1043. [CrossRef]

27. Sartori, T.; Menegalli, F.C. Development and characterization of unripe banana starch films incorporated with solid lipid microparticles containing ascorbic acid. Food Hydrocoll. 2016, 55, 210-219. [CrossRef]

28. Marotti, M.; Piccaglia, R.; Giovanelli, E.; Deans, S.G.; Eaglesham, E. Effects of variety and ontogenic stage on the essential oil composition and biological activity of fennel (Foeniculum vulgare mill.). J. Essent. Oil Res. 1994, 6, 57-62. [CrossRef]

29. Villalobos, R.; Chanona, J.; Hernández, P.; Gutierrez, G.; Chiralt, A. Gloss and transparency of hydroxypropyl methylcellulose films containing surfactants as affected by their microstructure. Food Hydrocoll. 2005, 19, 53-61. [CrossRef]

30. Galus, S.; Kadzińska, J. Moisture Sensitivity, Optical, Mechanical and structural properties of whey protein-based edible films incorporated with rapeseed oil. Food Technol. Biotechnol. 2016, 54, 78-89. [CrossRef]

31. Zúñiga, R.; Skurtys, O.; Osorio, F.; Aguilera, J.; Pedreschi, F. Physical properties of emulsion-based hydroxypropyl methylcellulose films: Effect of their microstructure. Carbohydr. Polym. 2012, 90, 1147-1158. [CrossRef] [PubMed]

32. Socaciu, M.-I.; Fogarasi, M.; Semeniuc, C.A.; Socaci, S.A.; Rotar, M.A.; Mureşan, V.; Pop, O.L.; Vodnar, D.C. Formulation and characterization of antimicrobial edible films based on whey protein isolate and tarragon essential oil. Polymers 2020, 12, 1748. [CrossRef] [PubMed]

33. Salarbashi, D.; Tajik, S.; Ghasemlou, M.; Alibadi, S.S.; Noghabi, M.S.; Khaksar, R. Characterization of soluble soybean polysaccharide film incorporated essential oil intended for food packaging. Carbohydr. Polym. 2013, 98, 1127-1136. [CrossRef] [PubMed]

34. Sagoo, S.; Board, R.; Roller, S. Chitosan inhibits growth of spoilage micro-organisms in chilled pork products. Food Microbiol. 2002, 19, 175-182. [CrossRef]

35. Arciello, A.; Panzella, L.; Dell'Olmo, E.; Abdalrazeq, M.; Moccia, F.; Gaglione, R.; Agustin-Salazar, S.; Napolitano, A.; Mariniello, L.; Giosafatto, C.V.L. Development and characterization of antimicrobial and antioxidant whey protein-based films functionalized with Pecan (Carya illinoinensis) nut shell extract. Food Packag. Shelf Life 2021, 29, 100710. [CrossRef]

36. Bleoancă, I.; Enachi, E.; Borda, D. Thyme antimicrobial effect in edible films with high pressure thermally treated whey protein concentrate. Foods 2020, 9, 855. [CrossRef] 